\title{
LAS YESERÍAS DEL ORATORIO DE LA MADRAZA \\ DE YŪSUF I, GRANADA. APORTACIONES DE LA DOCUMENTACIÓN GRÁFICA A LA DETERMINACIÓN DE ZONAS ORIGINALES Y AÑADIDOS EN EL ESTUDIO PRELIMINAR
}

\author{
THE PLASTERWORK OF THE ORATORY OF THE YŪSUF I \\ MADRASA IN GRANADA. CONTRIBUTIONS FROM GRAPHIC \\ DOCUMENTATION TO THE TASK OF LOCATING ORIGINAL \\ AND ADDED AREAS CARRIED OUT IN THE PRELIMINARY \\ STUDY
}

\author{
Ana García Bueno \\ Ariadna Hernández Pablos \\ Víctor J. Medina FlóReZ \\ Universidad de Granada
}

\section{Introducción*}

El estudio de las yeserías de la Madraza presenta una gran complejidad ya que se trata de un monumento que se ha mantenido en

* Este trabajo se ha desarrollando gracias a la financiación de dos Proyectos de Investigación: "El color de los revestimientos murales en la arquitectura andalusí", Ministerio de Educación, Política Social y Deporte (HUM 2005-03995/ARTE), y "Estudio y conservación de la decoración arquitectónica de tradición islámica", Proyecto de Excelencia de la Junta de Andalucía (HUM-02829). Queremos hacer constar nuestro agradecimiento a la Universidad de Granada, por encargarnos el estudio de las yeserías, especialmente a Dña. Elena Díez Jorge, Vicerrectora de Patrimonio, Infraestructura y Equipamiento en el momento en el que se realizó dicho trabajo. Así mismo queremos hacer constar nuestro agradecimiento a Virginia González Alcalde, que desempeñó funciones de apoyo en las labores de documentación y a Beatriz Martín Peinado, Restauradora (empresa TARMA), por la colaboración prestada durante los meses en los que estuvimos trabajando in situ. A D. Antonio Almagro Gorbea (EEA, CSIC, Granada), por facilitarnos los primeros dibujos realizados mediante fotogrametría, que nos permitieron hacer unos esquemas iniciales sobre los que trabajar hasta que nuestros dibujos provisionales estuvieron listos. Y, finalmente, a los profesores Cruz Cabrera y Gómez Moreno (Universidad de Granada) por facilitarnos el informe histórico, lo que nos permitió orientar, en un primer momento, nuestro trabajo. 
uso de forma continuada y que, además, ha estado dedicado a distintas funciones. Por tanto, ha sufrido numerosas actuaciones para su adecuación funcional en cada período; igualmente, la decoración ha experimentado adaptaciones según los gustos de cada momento.

Del estudio histórico realizado por José Manuel Gómez-Moreno Calera y José Policarpo Cruz Cabrera ${ }^{1}$, y de la observación detallada de la superficie decorada se deduce que las yeserías han soportado diversas intervenciones que, en muchos casos, al haber sido realizadas aplicando criterios al estilo de Viollet-Le-Duc - reconstruyendo las partes afectadas imitando el original e incluso ocultándolo con repintes generalizados que cubren toda la superficie para igualar así los acabados - , resultan difíciles de diferenciar. Con esta intención se desarrolla una metodología de trabajo que nos permita, en la medida de lo posible, identificar los restos originales y determinar a qué periodo corresponde cada zona.

El proceso de trabajo que requiere la ejecución de un proyecto de restauración de estas características dificulta la posibilidad de obtener el máximo partido a la investigación. Los presupuestos dedicados al estudio de materiales y los plazos de ejecución son habitualmente factores limitadores. Sin embargo, hasta ahora, en el caso de la Madraza se ha podido de realizar este trabajo, gracias al interés de la Universidad de Granada, propietaria del monumento y gracias también a la posibilidad de contar con los medios de nuestro equipo de investigación ${ }^{2}$ y los recursos de nuestros proyectos de $\mathrm{I}+\mathrm{D}^{3}$. Por ello consideramos que este modelo de colaboración tiene un gran interés - desarrollo de la investigación y transferencia de resultados-, y se debería mantener este tipo de actuación interdisciplinar, tanto aquí, máxime ahora que acaban de dar comienzo los trabajos de restauración en el monumento, como en otros casos cuyo interés así lo justifique.

${ }^{1}$ Cruz Cabrera, J.P. y Gómez-Moreno Calera, J.M.; "Estudio histórico-artístico del palacio de la Madraza, antigua casa del Cabildo de Granada", en R. López Guzmán y Mª. Díez Jorge (eds.), La Madraza: pasado presente y futuro, Granada, 2007.

${ }^{2}$ Laboratorio de Arqueología y Arquitectura de la Ciudad - LAAC - (código HUM104 del Plan Andaluz de Investigación), es un grupo multidisciplinar cuyos componentes pertenecen al Consejo Superior de Investigaciones Científicas (CSIC) y a las universidades de Granada y Sevilla.

${ }^{3}$ Véase nota *.

Al-Qanțara (AQ) XXXI 1, enero-junio 2010, pp. 257-267 ISSN 0211-3589 


\section{Metodología}

Tras una primera observación de la obra, se documentó fotográficamente en detalle toda la superficie de las yeserías. La proximidad del punto de la toma fotográfica - desde el mismo andamionos proporciona una mejor resolución y calidad de imagen, $\mathrm{y}$ también una gran abundancia de material gráfico.

Para resolverlo y poder localizar unívocamente las imágenes, dada su similitud al tratarse de elementos decorativos que se repiten, organizamos la zona del encuadre fotográfico a partir de una cuadrícula que subdividía los paramentos en función de su estructura formal, motivos ornamentales o a las líneas de unión de placas. En cada uno de los recuadros generados se colocó una pequeña etiqueta, de diferente color según el paramento, con la nomenclatura asignada ${ }^{4}$. De este modo se garantizó con absoluta fiabilidad la identificación correcta de cada zona.

Seguidamente se realizaron calcos de los diferentes elementos de la superficie, a partir de los cuales se realizó la restitución gráfica de toda la superficie. Sobre estos dibujos se fueron marcando todos los aspectos de interés observados durante el examen organoléptico, tales como las líneas de unión de placas, restos de policromía, alteraciones (sales, grietas, oquedades, etc.) y demás detalles decorativos que pudieran pasar desapercibidos con una visión más general. De igual modo, se señaló en ellos toda la información recogida en las siguientes fases del trabajo, localizando aquellos datos que pudieran resultar de interés para el estudio - tales como el lugar de la toma de muestras ${ }^{5}$ - , así como los resultados obtenidos a partir de cada una de ellas y su interpretación - por ejemplo, diferenciando, a partir de tramas y códigos cromáticos, las zonas en las que identificamos pigmentos modernos, que corresponden inequívocamente a una restauración, de las que estaban policromadas con pigmentos que podrían ser originales-.

\footnotetext{
${ }^{4}$ Utilizamos una clave alfanumérica que permite identificar en todo momento a qué zona exacta corresponde cada foto.

${ }^{5}$ Más detalles sobre metodología y gráficos de alteraciones en: García Bueno, A., Medina Flórez, V.J. y Hernández Pablos, A., "Estudio previo a la restauración de las yeserías del oratorio de la Madraza (metodología y avance de resultados)", en R. López Guzmán y $\mathrm{M}^{\mathrm{a}} \mathrm{E}$. Díez Jorge (eds), La Madraza: pasado presente y futuro, Granada, 2007, 277-304.
} 
Este proceso de documentación gráfica se constituyó en un instrumento de trabajo de gran utilidad en tanto que, por una parte, nos proporcionaba la posibilidad de valorar la técnica de ejecución de las yeserías — podemos saber si han sido realizadas a molde o han sido talladas - al comparar y analizar formalmente sus motivos ${ }^{6} \mathrm{y}$, por otra, nos permitía localizar conjuntamente toda la información obtenida y contrastar así simultáneamente los datos del análisis formal y material.

\section{Resultados: valoración sobre la identificación de zonas originales y añadidos}

El estudio se ha desarrollado sobre toda la superficie de la decoración en yeso del oratorio, seleccionando para este artículo los dos sectores que resultan más representativos de las diferentes situaciones que nos encontramos en el conjunto de las yeserías de la Madraza: la zona inferior del muro I (Fig. 1), que conserva una mayor cantidad de policromía original y el muro del mihrāb (Fig. 2) en cuya parte baja, pese a tener constancia, por fotografías históricas, de que persistían los morteros originales, y por tanto la mayor parte del relieve, la policromía de la restauración realizada a comienzos del siglo xx oculta cualquier resto de policromía original que pudiera conservarse.

\section{Muro I (zona baja) (Fig. 1)}

Se han seleccionado los niveles inferiores, por conservar una considerable superficie de yeserías originales con restos de la policromía inicial. Por otra parte, las características materiales y la textura del mortero coinciden con la que presentan las zonas que no plantean dudas en su identificación (color más oscuro y granulometría mayor). Además, la calidad de relieve, modulación y cambios de nivel en el entrecruzamiento de los motivos, en este caso las palmas lisas y pimientos que constituyen la mayor parte de la decoración, corro-

${ }^{6}$ García Bueno, A., Medina Flórez, V.J. y González Segura, A., "La policromía de las yeserías del oratorio de la Madraza de Yūsuf I, Granada. Aportaciones del estudio de materiales en la identificación de zonas originales y añadidos", en este mismo número de Al-Qantara.

Al-Qanțara (AQ) XXXI 1, enero-junio 2010, pp. 257-267 ISSN 0211-3589 
bora esta apreciación. No obstante no podemos descartar que, debajo de algunas zonas cubiertas por policromía moderna, pudieran existir morteros que correspondientes a intervenciones anteriores.

Si comenzamos a mirar por la parte alta del esquema (decoración geométrica) de izquierda a derecha, las dos primeras placas parecen originales, aunque muy degradadas por las sales. Las siguientes plantean dudas por el buen estado de conservación de la policromía moderna que oculta las cualidades materiales, sin embargo pensamos que pueden ser mayoritariamente originales (Fig. 1).

La epigrafía, que rodea el arco de pabellón decorado con paños de «sebka», parece original, aunque se encuentre enormemente degradada por la humedad y presencia de sales. Bajo la pintura moderna desprendida se observan restos de la original. Como en casos anteriores, la parte derecha puede tener reparaciones que se encuentren enmascaradas por el policromado. La zona izquierda, como se aprecia en la Fig. 1, se retiró durante la intervención de urgencia, ya que corría peligro de desprendimiento, esta zona se conserva aunque en este momento no esté in situ.

Creemos que el arco de pabellón, decorado con «sebka» y rematado por mocárabes, es original prácticamente en su totalidad. Únicamente la parte inferior de estas placas parece retocada en los morteros, sin embargo es difícil definir la unión entre la parte original y el añadido, ya que está oculta por la "repolicromía". Como se puede observar en los esquemas, las uniones de placas (marcadas en los gráficos con líneas discontinuas) se ven muy claramente.

La zona inmediatamente inferior, el triángulo que se forma bajo el arco de pabellón (Fig. 1), presenta considerables restos de decoración pintada original, sobre todo en los mocárabes. Está realizada a pincel, con un finísimo trazado que contrasta con la burda decoración que encontramos en otras zonas equivalentes, realizadas durante las últimas restauraciones.

Además debemos destacar que las lagunas permiten observar la textura y el color del mortero original. Éste, de color oscuro, parece del tipo de los habitualmente empleados en yeserías talladas, algo lógico en esa parte ya que la decoración no responde a un módulo repetitivo y no se detectan líneas de unión de placas; la analítica también nos lo confirma. Queda por tanto evidenciada la utilización de ambas técnicas (talla y moldes) de forma simultánea, la elección de una u otra dependería de las características del motivo a realizar. 
Respecto al nivel que incluye el paño de «sebka» y los arcos dobles de la zona inferior, identificamos como yesería original al primero, puesto que, tanto el examen organoléptico como la analítica así nos lo indican, mientras que los arcos se realizaron, muy probablemente, en la restauración (Fig.1).

\section{Muro del miḥrāb (Fig. 2)}

En primer lugar debemos decir que, en esta zona, hemos contado con la información valiosísima de las fotografías de archivo que nos han facilitado los profesores Gómez-Moreno Calera y Cruz Cabrera. En una de ellas, tomada en $1893^{7}$, se puede observar que la parte inferior izquierda del arco del mihrāb estaba prácticamente pérdida y la derecha muy dañada. Si observamos en la actualidad esta zona, parece repuesta, sin embargo tras un estudio más detallado, podemos decir que la mayoría de las dovelas son las originales aunque, eso sí, retocadas. A pesar de que en la foto antigua se puede ver la clave en relativas buenas condiciones, en la actualidad se encuentra muy rehecha. Esta afirmación puede hacerse a partir de la observación de la textura y del color de los morteros, pero también de la calidad del relieve; las palmas son más planas y no presentan la ondulación característica de las otras dovelas que son claramente originales.

En los otros niveles, la analítica coincide con las características de las yeserías a molde, aunque con reposiciones puntuales, que no podemos cuantificar ya que el buen estado de la policromía de la restauración lo impide. Además encontramos reposiciones evidentes como la de la placa derecha de la epigrafía que enmarca este paño. En general podemos decir que aquí parece conservarse una parte muy importante de las yeserías originales, así nos lo indican la calidad del relieve y los resultados de la analítica, sin embargo, el nivel de ocultamiento de las capas originales, por el estado de conservación de los repintes, es tan considerable que no podemos cuantificar la superficie de mortero reintegrada. Los resultados de la analítica del triángulo que se forma bajo los mocárabes indican que el morte-

\footnotetext{
${ }^{7}$ La imagen aparece en Almagro Cárdenas, A., Museo granadino de antigüedades árabes, Granada, reed. 1899.
}

Al-Qanțara (AQ) XXXI 1, enero-junio 2010, pp. 257-267 ISSN 0211-3589 
ro corresponde al de una yesería tallada y por tanto probablemente original.

Otra zona que planteaba dudas, a priori, es la cartela de epigrafía cúfica con fondo de palmas lenticuladas, ya que su policromía presenta actualmente un estado de conservación casi impecable. Esta zona se encuentra prácticamente completa en la foto de 1893, aunque el nivel de definición de la misma no nos permite afirmar que entonces no hubiera pequeñas lagunas de mortero. Por el estado de conservación de ese momento debemos suponer que las habría y que, durante la restauración de Emilio Hernández ${ }^{8}$, se repasó el relieve y se repintó. Esta intervención es la que le da ese aspecto tan nuevo, a pesar de ello consideramos que la mayor parte de la zona es original. Como se puede ver en el esquema, creemos que están muy retocadas la clave y las dovelas marcadas en color gris claro con trama de líneas horizontales, así como que están claramente repuestas las que ocupan la zona inferior del arco, que en la imagen marcamos en gris más oscuro. Así mismo, son repuestas las cartelas epigráficas de las impostas del arco y la parte inferior de la epigrafía que rodea el mismo. El resto debe tener abundantes retoques de yeso y, por supuesto, está completamente repintado, pero, como hemos dicho, parece original.

Los resultados de la analítica de morteros de la cartela epigráfica de palmas lenticuladas indican que se realizó mediante talla. Las demás muestras en esta zona corresponden a la restauración, en el caso de la policromía, pero no así en el de los morteros, en los que se identifica la existencia de restos de morteros tallados originales. En algunas muestras se detectan capas de policromía original subyacente que en ocasiones no coinciden con el color aplicado en las reposiciones de la restauración ${ }^{9}$.

\section{Conclusiones}

En primer lugar, podemos decir que el sistema de documentación elaborado mediante calcos y dibujos realizados a partir de los mismos ha sido una herramienta fundamental para el estudio de las

${ }^{8}$ Gómez-Moreno González, M.A., Guía de Granada, Granada, 1994, 2, 194, apéndice $1.067 \mathrm{~b}$.

${ }^{9}$ García Bueno, Medina Flórez y González Segura, "La policromía de las yeserías".

Al-Qanțara (AQ) XXXI 1, enero-junio 2010, pp. 257-267 ISSN 0211-3589 
yeserías de la Madraza, que nos ha permitido conocer puntualmente las características y el estado de conservación de la superficie decorada. La transcripción de los datos de la analítica a estos dibujos, junto a la observación muy precisa de toda la superficie decorada, ha facilitado enormemente la posibilidad de efectuar una evaluación comparada, teniendo en cuenta la gran cantidad de datos aportados por esta investigación.

En cuanto a las yeserías, existen diversas situaciones: la primera a tener en cuenta es aquella en la que se conservan restos con policromía original, lo que ofrece un gran interés no sólo para conocer las características y el aspecto inicial que debía tener (aunque éstos restos estén tremendamente degradados), sino también para tener un patrón de referencia a la hora de estudiar zonas que plantean dudas.

Otra situación es la que corresponde a zonas de yeserías originales ocultas por la policromía de la restauración de Emilio Hernández, aunque con posibles retoques puntuales; aquí los morteros son mayoritariamente originales. Finalmente hay otras partes en las que se repusieron placas completas de yeserías y que, por tanto, no presentan restos de los materiales auténticos (ni morteros ni capas de policromía).

Una de las aportaciones más interesantes de este trabajo es la identificación y localización del uso de los dos tipos de técnica que se emplearon para la ejecución de estas yeserías: la talla y los moldes. Aunque autores como Fernández Puertas ${ }^{10}$ consideran que las yeserías talladas son propias del primer periodo de arte Nazarí y que más tarde se desarrollarían las técnicas de moldes — nuestro equipo ha comprobado que, efectivamente, en un primer momento es así; por ejemplo, las yeserías del Cuarto Real de Santo Domin$\mathrm{go}^{11}$ de Granada se realizaron enteramente mediante técnicas de talla-, pero que este procedimiento no desparece completamente en una segunda etapa, sino que convive con los moldes. La utilización de una u otra técnica está en función de la extensión y del motivo decorativo empleado, de manera que, cuando es relativamente reducido, se opta por el procedimiento de talla mientras que, cuando es

${ }^{10}$ Fernández Puertas, A. (ed.), The Alhambra I. From the ninth century to Yusuf I (1354), Londres, 1997, 92.

${ }_{11}$ García Bueno, A. y Medina Flórez, V.J., "The Nașrid plasterwork at Qubba Dār al-Manjara L-Kubrà in Granada: Characterisation of materials and techniques", Journal of Cultural Heritage, 5 (2004), 75-89.

Al-Qanțara (AQ) XXXI 1, enero-junio 2010, pp. 257-267 ISSN 0211-3589 
una superficie amplia y un tema que se repite, se emplean los moldes. Un ejemplo de ello son las yeserías de la portada de la C/ San Buenaventura del Albayzín, Granada ${ }^{12}$, que a pesar de corresponder a un periodo tardío, se realizan enteramente talladas; las dimensiones reducidas de esta portada hacen que no resulte operativo realizar moldes para su ejecución, sobre todo teniendo en cuenta la enorme pericia de los artesanos. En el caso concreto de la Madraza, se han localizado las distintas zonas correspondientes a cada tipo de procedimiento. Así se confirma que las superficies irregulares y las epigrafías cuyo texto no se repite se hacen mediante talla, mientras que, cuando el motivo se reproduce para cubrir superficies más amplias de la decoración, se realizan a molde.

A pesar de que este estudio haya sido realizado en profundidad y que los resultados sean concluyentes, no podemos olvidar que las deducciones obtenidas a partir de un examen previo, por exhaustivo que éste sea, no pueden ser considerados categóricamente, ni por tanto extrapolados al conjunto de toda la obra, ya que siempre se trata de datos puntuales.

Por ello, en una obra de estas características, en la que se han repetido las superposiciones y restauraciones de forma sistemática a lo largo de su historia, la identificación material plantea una gran complejidad, y únicamente podría considerarse agotada la investigación cuando se haga extensiva a la totalidad de la superficie, lo que sólo es posible con el desarrollo de una nueva fase del trabajo realizada simultáneamente a los trabajos de restauración. En ella se realizarían las catas necesarias, las cuales nos permitirían concretar la existencia de yesos originales conservados que pudieran permanecer ocultos por las capas de color de la restauración del XIX o enmascarados por su mal estado de conservación.

A pesar de ello, la información obtenida hasta ahora mediante el análisis de materiales constituye un complemento óptimo, no sólo para afrontar la restauración con máximas garantías, sino también para facilitar nuestro trabajo y el de futuros investigadores.

12 García Bueno, A., Medina Flórez, V.J. y Hernández Pablos, A., "Intervención de urgencia en una casa musulmana de la calle San Buenaventura n², Albayzín, Granada", en II Congreso del grupo español del IIC. Intervención en Conservación y Restauración, Barcelona, 2005, 359-366. 

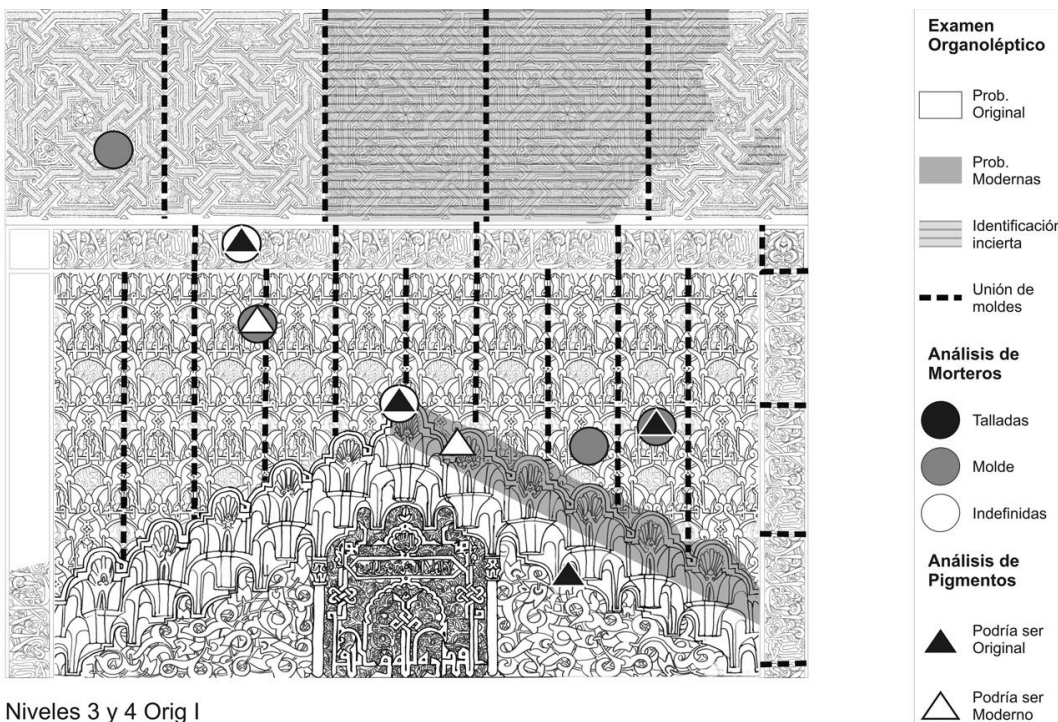

Niveles 3 y 4 Orig I

Moderno

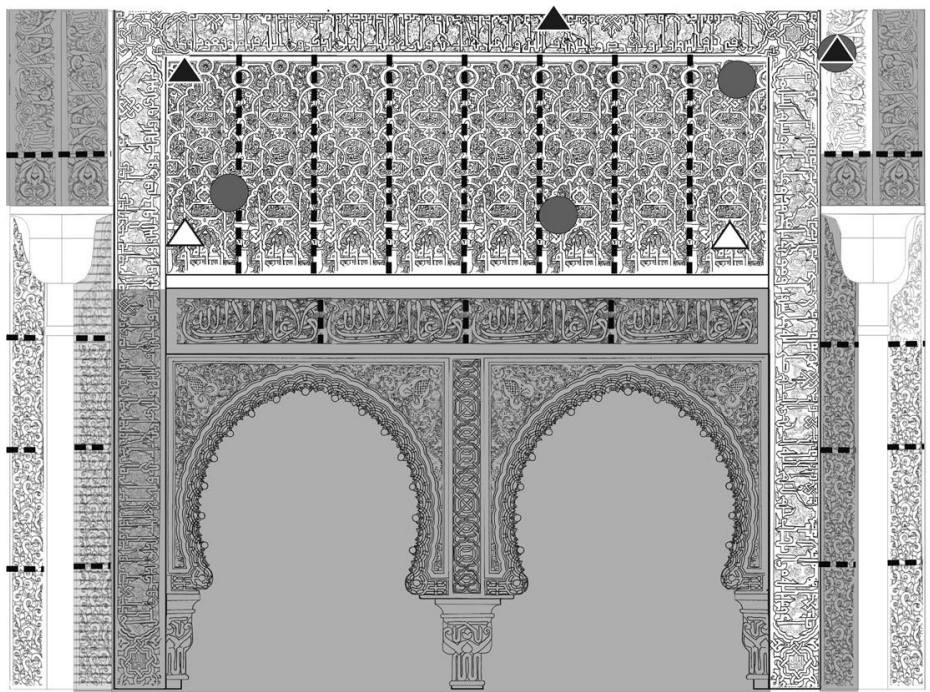

Niveles 5, 6, C1 y C2 Orig I

Figura 1

Al-Qanțara (AQ) XXXI 1, enero-junio 2010, pp. 257-267 ISSN 0211-3589 
Las yeserías del Oratorio de la Madraza de Yūsuf I, Granada. Aportaciones ... 267
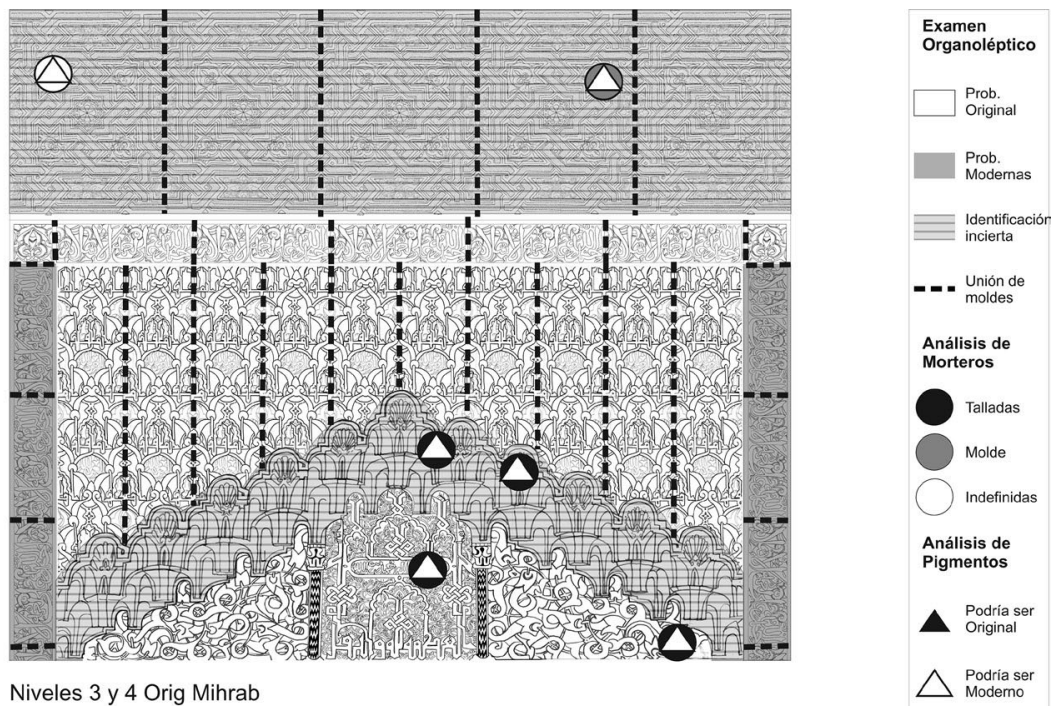

Niveles 3 y 4 Orig Mihrab

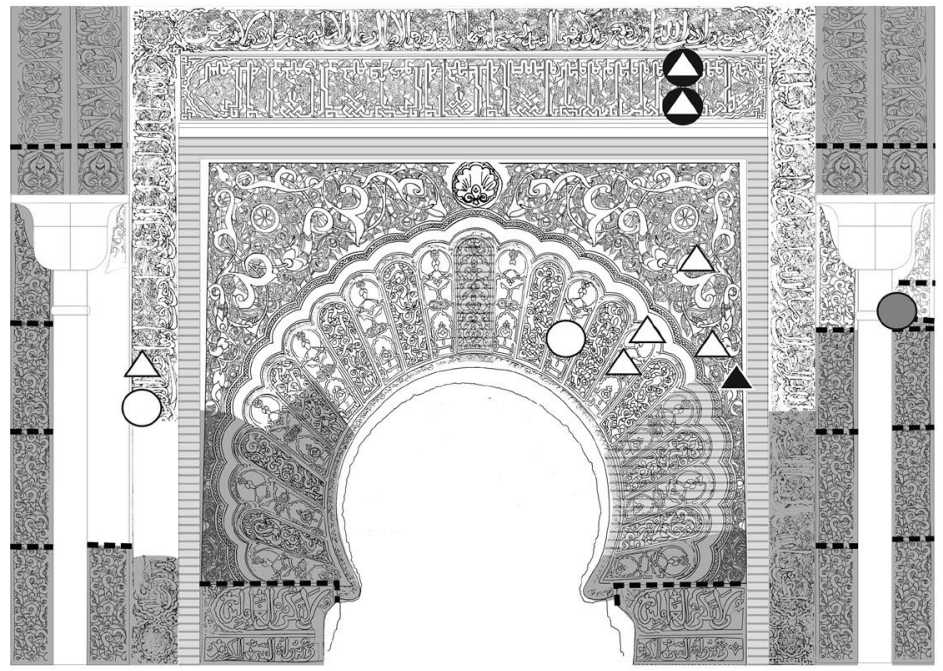

Niveles 5, 6, C1 y C2 Orig Mihrab

Figura 2

Recibido: $04 / 12 / 2008$

Aceptado: 24/06/2009

Al-Qanțara (AQ) XXXI 1, enero-junio 2010, pp. 257-267 ISSN 0211-3589 